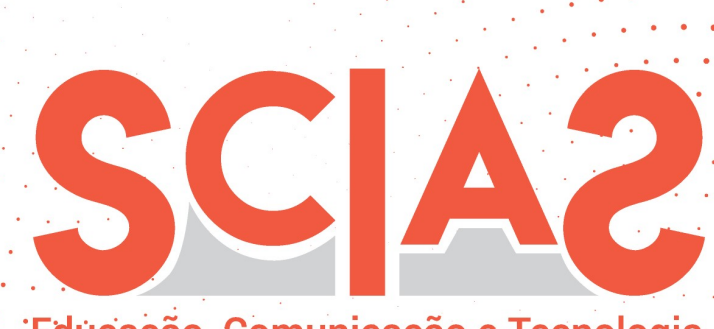

Educuçaçã̉o, Comunicação e Tecnologia

Atribuição BB CY 4.0

\title{
Os piratas da imagem: A popularização do videocassete no Brasil e as preocupações com a pirataria em vídeo
}

Enio Everton Arlindo Vieira ${ }^{1}$

\section{Resumo}

Este artigo tem a função destacar algumas das preocupações e inquietações causadas pela chegada da tecnologia de reprodução caseira de filmes disponibilizada pelos vídeos e fitas de vídeo cassetes no Brasil, com foco na viabilidade de produção de cópias ilegais de obras cinematográficas - a pirataria em vídeo. A popularização de tal tecnologia preocupava a indústria, que temia perder em vendas de vídeos, e até mesmo um esvaziamento dos cinemas.Nos baseamos, como referencial teórico, em escritos de estudiosos já consolidados como Peter Burke, Marcos Napolitano, Walter Benjamin, Fernando Novais, Renato Ortiz, entre outros. Como fontes primárias nos utilizaremos de edições diversas da revista SOMTRÊS, a primeira revista especializada em equipamentos de som e música produzida no Brasil.

\section{Palavras-chave}

História. Pirataria. Mídia. Jornalismo. Vídeo.

Recebido em: 23/02/2020

Aprovado em: 21/07/2020

\footnotetext{
${ }^{1}$ Mestre pelo programa interdisciplinar em “Educação, Arte e História da Cultura” pela Universidade Presbiteriana Mackenzie de São Paulo.

e-mail: teacherenio@gmail.com
} 


\section{The pirates of the image: The popularization of the videocassette recorder in Brazil and concerns about video piracy}

\section{Abstract}

This article aims to highlight some of the concerns caused by the arrival of technology for home tape reproduction of films made available by videocassettes and videotapes in Brazil, focusing on the feasibility of producing illegal copies of cinematographic works - videopiracy. The popularization of such technology worried the industry, which feared losing in sales of videos, and even an emptying of cinemas. We are based, as a theoretical reference, on writings of already established scholars such as Peter Burke, Marcos Napolitano, Walter Benjamin, Fernando Novais, Renato Ortiz, among others. As primary sources we will use different editions of SOMTRÊS magazine, the first magazine specialized in sound and music equipment produced in Brazil.

\section{Keywords}

History. Piracy. Media. Journalism. Video. 


\section{Introdução}

Em abril de 1981, a revista SOMTRÊS, auto intitulada a primeira revista de música e som do Brasil ${ }^{2}$, anunciava em sua capa que o Brasil havia entrado na era do vídeo, mas mal havia o país aderido a tal novidade, já era vítima do "maior golpe dos piratas do teipe e do cassete"3. Se a pirataria musical já era um preocupação constante nas páginas da revista, dada a facilidade das técnicas de reprodução cassete (como veremos mais adiante), a novidade do videocassete já chegava ao Brasil reproduzindo as práticas de cópias caseiras e venda de fitas ilegais, técnicas já previamente conhecidas pelos consumidores de música brasileiros, graças a popularização das tecnologias de reprodução de fitas cassete. Para este artigo, nos utilizamos, como fonte primária, de edições diversas da revista SOMTRÊS4, em especial o número vinte e oito, publicado em abril de 1981, que trazia a reportagem Os piratas do som e da imagem, artigo que servirá de base e ponto de partida para este trabalho. Todas as edições da revista SOMTRÊS podem ser encontradas na sala Sérgio Milliet da Biblioteca Municipal Mário de Andrade, no centro da cidade de São Paulo.

Com o intuito de elucidar algumas informações sobre o momento inicial de popularização das fitas e gravadores de videocassete no Brasil, e nos baseamos, como referenciais bibliográficos, em especialistas em história cultural, como Peter Burke, Marcos Napolitano, Renato Ortiz, Fernando Novais, além de Walter Benjamin e seus escritos sobre a reprodutibilidade técnica das obras de arte, entre outros.

\section{Revista SOMTRÊS}

Se auto intitulando como a primeira revista de som e música do Brasil, a Revista SOMTRÊS foi publicada, pela primeira vez, em janeiro de 1979, e durou exatos

\footnotetext{
${ }^{2}$ KUBRUSLY, Maurício. Editorial. Revista SOMTRÊS, São Paulo, no ${ }^{13}$, jan. de 1980, p. 10.

3 Segundo anúncio de capa de Revista SOMTRÊS, nº 28,abr. de 1981. A grafia "teipe", versão aportuguesada do termo em inglês "tape" (fita), era utilizada dessa forma na publicação original e será respeitada quando citarmos a fonte primária. Em outros casos, utilizaremos o término "fita de vídeo cassete".

4 A revista sempre escrevia seu próprio nome com letras maiúsculas. Respeitaremos a grafia utilizada pela publicação ao longo deste trabalho.
} 
dez anos. Extinta em janeiro de 1989, publicou um total de 121 edições, editada pela Editora Três de São Paulo, e vendida por todo o país. Seu intuito era, ao menos no primeiro momento, oferecer uma alternativa aos chamados "audiófilos" (fãs de música e novidades em equipamentos de som, de uma maneira geral) às publicações importadas que, além de custarem preços exorbitantes, exigiam o conhecimento de uma língua estrangeira normalmenteo inglês - echegavam às bancas brasileiras com uma grande defasagem no que diz respeito aos lançamentos dos equipamentos de som e sua disponibilidade no mercado. Era "uma publicação brasileira, sem sotaque, para quem gosta da melhor música e exige o melhor som" 5 .

No entanto, pouco a pouco as notícias sobre as novidades em equipamentos de vídeo se faziam mais presentes em suas páginas, que frequentemente apresentavam as novidades na área de imagem. Já na sua edição de número quatro, em abril de 1979, sua capa destacava a criação do vídeo disco, um LP que utilizava raio laser ao invés de agulha para ler cada filme de longametragem ${ }^{6}$. Em agosto do mesmo ano, o jornalista Nestor Natividade apontava que a propagação dos aparelhos reprodutores de videocassete auxiliariam o consumidor a eleger a hora de assistir seus programas preferidos quando bem entendessem, celebrando o fim da "tirania de uma programação estática dos canais de TV." 7 Sem embargo, a reportagem de abril de 1981 encara o fim dessa tirania de modo muito mais agressivo, pois reconhece que com a chegada do " vídeo-teipe, surgiram imediatamente os 'piratas da imagem' gravando escondido ou simplesmente roubando concertos, filmes, noticiários, reportagens, tudo"8.

Assim que, ao chegarmos na edição de abril de 1981, surpreende o fato de a pirataria de vídeo haver chegado ao Brasil antes mesmo da inauguração da

5KUBRUSLY, Maurício. Editorial. Revista SOMTRÊS, São Paulo, nº 1, jan. 1979, p. 05 ${ }^{6}$ Capa. Revista SOMTRÊS, São Paulo, ${ }^{\circ}$ 04, abr. de 1979.

7 NATIVIDADE, Nestor. A fórmula para o vídeo de amanhã. Revista SOMTRÊS, São Paulo, no o8, ago. de 1979, p. 52.

8 MENEZES, Marco Antônio. Os piratas do som e da imagem. Revista SOMTRÊS, São Paulo, nº 28, abr. de 1981, p. 52. 
fábrica da Sony em Curitiba9, fato ocorrido em 1978, que possibilitaria a fabricação de aparelhos de áudio e vídeo no país. Isso nos faz questionar em que situação se encontrava o país no final dos anos 1970 e início dos 1980, momento no qual, simultânea à abertura da fábrica da Sony no Brasil, SOMTRÊS chegava às bancas e os aparelhos de reprodução em vídeo - e em fita de áudio - cassetes e popularizavam. Nos voltaremos para o contexto histórico do momento aqui estudado agora.

\section{Entre o milagre e a crise - o Brasil entre 1978 e 1982}

Surgida em janeiro de 1979, a revista SOMTRÊS teve uma vida de dez anos, vendo sua última publicação nas bancas em janeiro de 1989, na edição de número 121. O período escolhido para este estudo é oportuno por uma série de fatores, pois consiste no momento de industrialização que Ortiz (2003), Mello e Novais (1998) chamam de inserção forçada ao "Capitalismo Tardio", promovida pelos governantes militares nos anos entre os anos de 1964 e 1985, principalmente no que diz respeito à década de 1970, quando ocorreu um vertiginoso crescimento econômico que ficaria conhecido como o "Milagre Brasileiro". Ao longo da década de 1970, o produto interno bruto do país passou por "um crescimento contínuo [...], com taxas anuais em torno de 11\%" (SILVA, 2013, p. 260). Ao lado dessa prosperidade econômica, Marcos Napolitano (2014) aponta que os meios de comunicação e a indústria da cultura conheceram uma popularização sem precedentes até então na história do Brasil.

Com o crescimento econômico, os bens culturais passaram a ser consumidos em escala industrial: telenovelas, noticiários, coleções de livros e fascículos sobre temas diversos, revistas [...] demonstravam a nova tendência industrial e "massiva" do consumo cultural, que se consolidaria de vez na segunda metade da década de 1970. Dessa maneira, via bancas de jornal e televisão, a cultura escrita chegava aos segmentos mais pobres da população - sobretudooperários qualificados, pequenos funcionários públicos e classe média baixa, como um todo. (NAPOLITANO, 2014, p. 82).

9 MENEZES, Marco Antônio. Os piratas do som e da imagem. Revista SOMTRÊS, São Paulo, nº 28, abr. de 1981, pp. 49-56. 
SOMTRÊS começa a ser publicada, justamente, quando os efeitos do "milagre" econômico já se esgotavam no fim dos anos de 1970, e teria início a década que será declarada como "perdida", devido a suas crises constantes após o milagre, e um aumento nos níveis de inflação. De acordo com Marcos Napolitano:

A inflação de 1980 chegou aos $110 \%$, marca histórica de 1964. [...] Mesmo recuando um pouco nos anos seguintes, a inflação ficou na faixa dos $90 \%$ ao ano. Os reajustes semestrais de salário apenas evitavam que a questão social saísse do controle, mas não impediam as perdas paulatinas no poder de compra de operário e da classe média. (NAPOLITANO, 2014, pp. 284-285).

Ademais, temos aqui a popularização de bens culturais, e a revista SOMTRÊS, chega às bancas junto com a disseminação de bens de consumo que mudariam a forma de como os audiófilos e os cinéfilos apreciariam suas músicas e filmes. Graças a veiculação das formas caseiras de gravação promovidas pelas tecnologias de gravadores de fitas e videocassetes, os cidadãos de classe média encontravam uma nova forma de consumir produtos culturais de áudio e vídeo:

A nova classe média está, em geral, plenamente integrada nos padrões de consumo moderno de massas, de alimentação, de vestuário, de higiene pessoal e beleza, de higiene da casa. Tem todas as maravilhas eletrodomésticas, inclusive a TV em cores, 21 polegadas (de 1972, quando começou a ser produzida, a 1979, foram vendidos cerca de 4,5 milhões de aparelhos). Tem telefone. Tira férias e viaja com a família pelo Brasil, de avião ou de carro; hospeda-se em hotéis "razoáveis". [...] O padrão de vida da nova classe média beneficia-se muitíssimo dos serviços baratos (MELLO e NOVAIS, 1998, pp. 631-632).

Com o esgotamento do milagre econômico, a crise já era vista no horizonte, e o que levaria os governos militares do país, que governaram o Brasil de 1964 a 1985, a buscar formas de modernizar o país e integrá-lo aos padrões de consumo dos países industrializados. Ortiz (2001) destaca que os governantes militares não necessariamente inventaram o "capitalismo brasileiro", mas inseriram o país nos processos de internacionalização do capital. Tanto em termos econômicos quanto culturais, essa integração forçada traria "consequências imediatas, pois, paralelamente ao crescimento do parque industrial e do mercado interno de bens materiais, fortalece-se o parque industrial de produção de cultura e o mercado de bens culturais" (ORTIZ, 2001, pp. 114-115). 
Dentre as medidas de fortalecimento do parque industrial e produção de cultura e bens culturais, seria construída, entre janeiro de 1980 e março de 1981, a fábrica da Sony em Curitiba, que em sua inauguração empregava 200 funcionários, mas pretendia gerar cinco vezes mais postos, chegando aos mil empregados em 1985, e tendo o privilégio de ser “a única fábrica japonesa a produzir videocassetes fora do Japão"10.

Dentre tantas mudanças ocorrendo, os videocassetes da Sony, assim como outros produtos de bens culturais, se sentiam ameaçados pela vulgarização das formas de reprodução caseira, o que levavam a uma inquietação nos âmbitos jurídico e econômico. Veremos agora os inconvenientes levantados por SOMTRÊS, no que diz respeito a pirataria de música e, principalmente, vídeos.

\section{O conceito de pirataria, e suas aplicações em cópias de vídeo}

Antes de mais nada, é importante aclarar o conceito de comércio pirata e de cópia pirata. Ainda que estejam muito próximos, afinal o comércio pirata consiste na compra de venda de produtos falsificados, nem toda cópia pirata é feita com intenções comerciais. O termo pirataria é limitado e não abarca as possibilidades distintas que as tecnologias de cópias e tipos de comércio nos quais o termo abrange. Temos a pirataria como definida por Ladeira (2013), de cópias - ora precárias, ora se passando por originais a ponto de enganar especialistas - que são vendidas em larga escala; temos as cópias caseiras, que podem ou não ser comercializadas, mas que em nenhum momento tentam simular as gravações originais, e que são possibilitadas graças a reprodutibilidade técnica, como teorizada por Walter Benjamin (2003); e há, ainda o bootleg, que consiste em álbuns que registram "basicamente de performances de shows (sobretudo os transmitidos pelas estações de rádio) e de material raro ou inédito.” (SANTOS, 2010, p. 84). Christiano Rangel dos Santos

${ }^{10}$ MENEZES, Marco Antônio. Os piratas do som e da imagem. Revista SOMTRÊS, São Paulo, $\mathrm{n}^{\circ}$ 28, abril de 1981, p. 51. 
destaca ainda que o termo bootleg não tem uma tradução direta para o português, e por se tratar, na maioria das vezes, de material raro e/ou inédito, e se diferem pois a "sua peculiaridade está no fato de as gravações não serem exatamente uma mera reprodução dos produtos musicais oficiais trabalhados pelas gravadoras, embora possam ser de artistas que possuem contrato com alguma empresa fonográfica” (SANTOS, 2010, p. 94).

As gravações caseiras, sejam elas de música ou de vídeo, possuem uma natureza própria, pois não se trata de produtos feitos com objetivo de lucro por parte de quem produz, ou uma falsificação de uma marca estabelecida que ludibria a quem compra, estando muito mais próxima da lógica do consumo dos bootlegs, produto destinados aos fãs incondicionais que, de uma maneira geral, buscavam, alternativas ao que é oferecido pelo mercado. Sem contar o fato que registros ilegais de apresentações ao vivo em vídeo servem de registros de icônicos momentos da História da música atual, noção reconhecida pela própria revista SOMTRÊS, que aponta que as cópias caseiras foram responsáveis "pela preservação de momentos que as produtoras oficiais jamais iriam considerar dignos de comercialização" 11 .

Pirataria, sim, mas uma pirataria às vezes muito útil. De que outra forma a posteridade teria, preservada perfeitamente, aquela noite inesquecível de 1948, com Maria Callas na Kundry de Parsifal, em Veneza? E o primeiro concerto elétrico de Bob Dylan, em Newport? Guardadas as proporções, são documentos da História moderna, na mesma medida que os respeitados monumentos da História antiga. ${ }^{12}$

Tais gravações de apresentações que jamais estiveram à venda no mercado são consideradas "momentos da vida cultural e musical gravados quase por acaso"13, sendo uma fatia do mercado que tendia a crescer os apreciadores de raridades em vídeo.

${ }^{11}$ MENEZES, Marco Antônio. Os piratas do som e da imagem. Revista SOMTRÊS, São Paulo, $\mathrm{n}^{0}$ 28, abr. de 1981, p. 53. Importante destacarmos que a revista não faz distinções entre "pirataria" e "cópias caseiras", tratando todo o tipo de cópia não autorizada como "pirataria".

${ }_{12}$ MENEZES, Marco Antônio. Os piratas do som e da imagem. Revista SOMTRÊS, São Paulo, nº 28, abr. de 1981, p. 52.

${ }_{13}$ MENEZES, Marco Antônio. Os piratas do som e da imagem. Revista SOMTRÊS, São Paulo, nº 28, abr. de 1981, p. 53. 
Outra grande vantagem das gravações em fitas de videocassetes, enquanto tecnologia, era a sua facilidade em ser gravada e regravada várias vezes. A própria efemeridade da tecnologia assinala uma forte característica da ${ }^{14}$ sociedade consumista, pois, diferente de, por exemplo, um disco, no qual suas faixas não podem ser alteradas ou mudadas de ordem, uma gravação em fita poderia ser completamente alterada, uma vez que o ouvinte (ou no caso das fitas de vídeo, o espectador) não quisesse mais desfrutar do conjunto de músicas (ou dos filmes) da gravação, o que coincide com a ideia de que "a vida de consumo não pode ser outra coisa senão uma vida de aprendizado rápido, mas também precisa ser uma vida de esquecimento veloz" (BAUMAN, 2008, p. 124).

A confusão entre definir o que é uma cópia para uso caseiro e a pirataria feita com o intuito de lucro levou a discussão sobre as fitas de videocassete para os tribunais estadunidenses. As produtoras de filmes "queriam simplesmente a proibição da venda e fabricação de gravadores e fitas" ${ }^{15}$, proibição essa que foi negada lhes foi negada, desde que as gravações caseiras não fossem comercializadas. O próprio órgão encarregado de combater a vídeo-pirataria nos Estados Unidos, o FBI, achava que era "mera tolice tentar evitar a gravação clandestina, depois que um filme é vendido à TV"16, não haveria motivo de fiscalizar sua comercialização. Mais complicado seria um caso como o clássico da ficção científica, O Império Contra-Ataca, segundo filme da saga Star Wars (Guerra nas Estrelas), "em que as fitas piratas chegaram ao comércio clandestino antes da estreia nos cinemas" 17 , o que, de fato, representava uma ameaça à bilheteria do filme. Como o cinema se sentia acossado com a popularização das formas de reprodução possibilitadas pelo videocassete é o assunto para o qual nos voltaremos agora.

${ }_{14}$ MENEZES, Marco Antônio. Os piratas do som e da imagem. Revista SOMTRÊS, São Paulo, no 28 , abr. de 1981, p. 54.

15 MENEZES, Marco Antônio. Os piratas do som e da imagem. Revista SOMTRÊS, São Paulo, no 28, abr. de 1981, p. 53.

${ }_{16}$ MENEZES, Marco Antônio. Os piratas do som e da imagem. Revista SOMTRÊS, São Paulo, ${ }^{0}$ 28, abr. de 1981, p. 53

${ }^{17}$ MENEZES, Marco Antônio. Os piratas do som e da imagem. Revista SOMTRÊS, São Paulo, n $^{0}$ 28, abr. de 1981, p. 52. 


\title{
Uma (suposta) ameaça para o mercado de filmes brasileiros
}

A preocupação em impedir a comercialização de fitas de videocassete pirateadas era mais preventiva que real. As dificuldades em copiar um filme, em comparação com as cópias de álbuns de música em fita cassete de áudio, eram consideravelmente maiores. Para copiar de uma fita para outra bastava "acoplar dois aparelhos e esperar o resultado", enquanto, para se duplicar um filme, no início dos anos 1980, o processo era, todavia, penoso e de alto custo.

\begin{abstract}
Para transformar um filme em fita, é preciso usar uma máquina especial, que custa aproximadamente $150 \mathrm{mil}$ dólares. Copiar uma fita em outra fita é mais uma tarefa para profissionais, a não ser que o pirata se contente com imagens sem azul, com interferência do som, etc. Felizmente - ouinfelizmente, para os donos legais dos direitos - firmasjaponesas estão utilizando uma copiadora que transformam duas horas de filme em duas de fita, com alta-fidelidade, em apenas cinco minutos. Até lá, a gravação será em "tempo real": um filme de duas horas leva duas horas para ser copiado, e cada cópia pirata tem de ser feita separadamente, a não ser que se disponha de um laboratório de vídeo, no valor de algumas centenas de milhares de dólares ${ }^{18}$.
\end{abstract}

No entanto, mesmo com todas essas dificuldades para se efetuar uma cópia, o mercado se preocupava. Se em países como os Estados Unidos e a França a vídeo-pirataria, enquanto forma de comércio, já era uma realidade19, países que estavam se inserindo no capitalismo consumista moderno, como o caso do Brasil e da América Latina, viam os aparelhos de videocassete se popularizarem cada vez mais, fazendo desses locais um mercado de "potencial paradisíaco"20. Isso levava as produtoras de filmes a tomar precauções, incluindo uma série de "defeitos" nas fitas de vídeo, falhas que só apareceriam nas cópias, como ruídos e limitações das cores. Ademais, pregavam mudanças nas legislações dos países,

${ }^{18}$ MENEZES, Marco Antônio. Os piratas do som e da imagem. Revista SOMTRÊS, São Paulo, no 28, abr. de 1981, p. 54.

${ }^{19}$ SOMTRÊS aponta que o número de fitas pirateadas no mercado informal em ambos Estados Unidos e França igualavam o número de aparelhos de videocassete vendidos. Nos Estados Unidos, esse número era de três milhões, e os números franceses não são revelados, mas a reportagem destaca que a França era o país campeão de pirataria de fitas de videocassete piratas na Europa.

${ }^{20}$ MENEZES, Marco Antônio. Os piratas do som e da imagem. Revista SOMTRÊS, São Paulo, ${ }^{\circ}$ 28, abr. de 1981, p. 52. 
tentando "estabelecer leis que obriguem o comprador a pagar-lhes uma 'taxa', no preço da aquisição de gravadores ou de fitas em branco" 21 .

A ideia de uma taxa compensatória não era exclusiva das produtoras de filmes, mas uma adaptação do imposto cobrado por fitas cassete em branco, em vigor em alguns países, como França, Alemanha, Holanda, Portugal e Espanha (HEYLIN, 1994, p. 241). Essa taxa era considerada uma medida compensatória por parte da indústria fonográfica, buscando, por um lado, desencorajar a compra de fitas cassetes virgem por usuários ávidos por efetuar gravações caseiras e, por outro lado, sendo "um meio de extorquir dinheiro de todos os usuários de fitas virgens para pagar por supostas violações de direitos autorais" (HEYLIN, 1994, p. 212). Clinton Heylin acusa essas taxas de extorsivas pelo fato que de que tal taxa não funcionaria como um sistema tradicional de pagamento de direito autoral, afinal, como pagar os direitos de algo inexistente, no caso de uma fita virgem em branco? O dinheiro geral iria direto para as gravadoras, e não para os artistas, levando as gravadoras a lucrar cerca de 70-80 milhões de libras, isso apenas considerando o Reino Unido, e causando um aumento de 100\% no preço das fitas cassete (HEYLIN, 1994, p. 238).

Contudo, a reportagem reconhece as limitações dessas atitudes proibitivas por parte das produtoras de vídeo. No âmbito legal, as produtoras enfrentavam vários processos litigiosos entre sindicatos e artistas, que todavia não recebiam sua parte dos lucros dos cassetes ${ }^{22}$. Sem entrar em maiores detalhes, SOMTRÊS acusa os grandes estúdios de Hollywood de "entesourar de modo egoísta, em seus arquivos, alguns dos maiores clássicos do cinema, que nenhuma TV consegue comprar" ${ }^{23}$, apontando a pirataria como um recurso do consumidor para degustar, mesmo contra a lei, um momento de cultura que se encontrava inacessível ao consumidor comum. A reportagem chega a sugerir que o melhor seria o lançamento das fitas originais (chamadas pelo autor de "fitas legais") no mesmo momento de estreia dos filmes no cinema, pois acreditava que isso

${ }^{21}$ MENEZES, Marco Antônio. Os piratas do som e da imagem. Revista SOMTRÊS, São Paulo, no 28, abr. de 1981, p. 54.

${ }_{22}^{2}$ MENEZES, Marco Antônio. Os piratas do som e da imagem. Revista SOMTRÊS, São Paulo, no 28, abr. de 1981, p. 54.

${ }_{23}$ MENEZES, Marco Antônio. Os piratas do som e da imagem. Revista SOMTRÊS, São Paulo, nº 28, abr. de 1981, p. 54. 
pouco influenciaria o mercado, já que a maioria das fitas comercializadas consistia de filmes pornográficos ${ }^{24}$ (50\% do mercado geral, sendo que $70 \%$ do mercado japonês da época consistia em fitas contendo filmes de sexo explícito).

Dentre as recomendações, SOMTRÊS faz advertências dos malefícios que uma fita pirata pode causar nos aparelhos de videocassete, pois fitas de má qualidade prejudicavam as cabeças magnéticas de gravação por serem "uma verdadeira lixa" 25 . Havia o risco de se comprar uma fita que prometia um filme, e ao chegar em casa havia outra gravação distinta da prometida na capa. Entretanto, SOMTRÊS termina a matéria recomendando as melhores lojas para se comprar fitas (legais e ilegais), tanto nos Estados Unidos quanto na França, inclusive divulgando os endereços desses locais. Isso sempre lembrando de confirmar a compatibilidade dos diferentes sistemas de gravação da época ("Pal-M no Brasil, NTSC nos Estados Unidos, Pal e Secam na Europa"), pois gravações incompatíveis tornariam a fita de videocassete inútil. Outra recomendação importante era de, no caso do leitor de SOMTRÊS se arriscar a comprar um filme gravado ilegalmente na França ("debaixo do balcão de uma lanchonete que serve deliciosas panquecas, no boulevard de Saint-Germain”), deveria tomar cuidado com a alfândega e, para os leitores que moravam em prédios, a presença de uma antena coletiva no condomínio, pois isso faria com que os vizinhos recebessem "as ousadias eróticas que você comprou em Paris".

Podemos ver que a posição da revista no que diz respeito às formas de pirataria - sejamelas as cópias caseiras ou a pirataria produzida em larga escala visando maiores lugares - éambígua, com momentos de condenação à prática nos âmbitos morais e jurídicos ("Por mais justo que fosse, Robin Hood era um ladrão"26); intercalando com opiniões que ora relativizam a pirataria, levantando sua importância em ter preservado apresentações importantes de grandes artistas, ora incentivando as práticas de cópias e vendas de fitas ilegais,

${ }^{24}$ MENEZES, Marco Antônio. Os piratas do som e da imagem. Revista SOMTRÊS, São Paulo, ${ }^{\circ}$ 28, abr. de 1981, p. 53.

25 MENEZES, Marco Antônio. Os piratas do som e da imagem. Revista SOMTRÊS, São Paulo, $\mathrm{n}^{\circ}$ 28, abr. de 1981, p. 56. Todas as citações contidas nesse parágrafo foram extraídas da mesma página 56 da reportagem original.

${ }_{26}$ MENEZES, Marco Antônio. Os piratas do som e da imagem. Revista SOMTRÊS, São Paulo, nº 28, abr. de 1981, p. 52. 
chegando até mesmo a oferecer os endereços de onde conseguir "ousadias eróticas" no caso de uma visita a Paris. A sugestão de que seus leitores poderiam comprar fitas de videocassete em viagens internacionais nos fazem pensar quem era o leitor de SOMTRÊS, assunto da próxima seção deste trabalho.

\section{O público leitor de SOMTRÊS}

Ao descrever a situação precária do povo brasileiro na década de 1980 no Brasil, Mello e Novais (1998) descrevem como os trabalhadores comuns estavam mergulhados na pobreza absoluta, e "bastava a ocorrência de algum percalço ou de alguma fatalidade para que a vulnerabilidade decorrente dos baixos salários ou da baixa renda se traduzisse em insuficiência alimentar, em precariedade habitacional, etc". (MELLO e NOVAIS, 1998, pp. 625-626). Entretanto, SOMTRÊS não era uma revista direcionada a trabalhadores das classes mais baixas, tendo inicialmente um caráter elitista, e sendo uma publicação destinada para quem pudesse, sobretudo, pagar pelos melhores equipamentos de som e vídeo. Dirigida aos audiófilos, o jornalista Carlos Barradas da Silva define o público alvo da revista como pessoas que dedicam interesse "aos assuntos de som, com o objetivo de ouvir música gravada em ótimas condições" ${ }^{27}$. Outras considerações que seguem na mesma matéria falam da importância de uma sala bem preparada acusticamente, de se ouvir boas gravações, na medida do possível, a não ser no caso de gravações antigas, pois neste caso o audiófilo deve buscar obter equipamentos que amenizem a precariedade da gravação original. Em outras palavras, uma família apertada em uma habitação de um ou dois cômodos não estaria apta para fazer parte do clube dos audiófilos. SOMTRÊS fazia parte, portanto, do conjunto de jornais e revistas que tiveram sua expansão no pós 64 "ancorada no crescimento da nova classe média, que tem renda suficiente para comprá-los" (MELLO e NOVAIS, 1998, p. 639). SOMTRÊS, mesmo tendo uma abrangência de público destinatário limitada.

Mas como era o campo editorial, em especial no que diz respeito às revistas, no Brasil pós milagre econômico? Um trecho do longo editorial de duas páginas da

${ }_{27}$ SILVA, Carlos Barradas da. A Questão dos Princípios. Revista SOMTRÊS, São Paulo, ${ }^{\circ}$ 1, jan. de 1979, p. 08. 
edição comemorativa de um ano de SOMTRÊS nas bancas nos fornece algumas dicas do que ocorria no Brasil na virada da década de 1970 para 1980.

Quem observa uma banca de jornais e revistas não pode imaginar que ainda haja brechas no meio daquele exagero de capas coloridas. Mas ainda há espaço para mais algumas, sim, particularmente nos escaninhos das publicações especializadas. Por exemplo: até o último janeiro de 70, o Brasil ainda não tinha a sua revista de som e música como existem dezenas nos Estados Unidos, Europa e Japão. Foi naquele janeiro que SOMTRÊS chegou. E agora, 13 meses depois, a primeira revista brasileira para quem gosta de som \& música completa seu primeiro ano ainda como a única no setor ${ }^{28}$.

A descrição bastante visual de uma banca de jornal da época, com um exagero de cores e praticamente nenhum espaço para novas publicações nos faz concluir que, pese a existência da censura, que todavia vigorava, havia uma enorme variedade de publicações. A falta de concorrência no quesito de publicações especializadas em equipamentos de som e música não diminui a multiplicidade de opções de leitura que os brasileiros tinham a sua disposição. Sem embargo, tal diversidade se dava dentro da lógica de crescimento promovida pelos governos militares, e o crescimento do campo editorial estava dentro do projeto de inserção do Brasil ao capitalismo tardio, tal como descrito por Marcelo Ridenti:

À sombra de apoios do Estado, floresceu também a iniciativa privada: criou-se uma indústria cultural, não só televisiva, mas também fonográfica, editorial (de livros, revistas, jornais, fascículos e outros produtos comercializáveis até em bancas de jornal), de agências de publicidade etc. Tornou-se comum, por exemplo, o emprego de artistas (cineastas, poetas, músicos, atores, artistas gráficos e plásticos) e intelectuais (sociólogos, psicólogos e outros cientistas sociais) nas agências de publicidade, que cresceram em ritmo alucinante a partir dos anos 1970, quando o governo também passou a ser um dos principais anunciantes na florescente indústria dos meios de comunicação de massa (RIDENTI, 2013, p. 155).

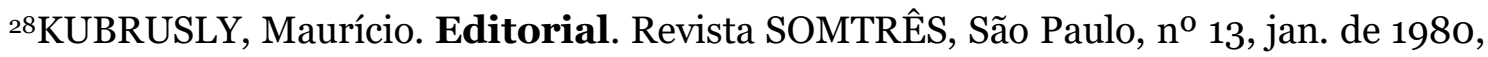
pp. 10-11. 
Por mais que fosse a única revista do setor de som, a bibliografia sobre o período nos faz duvidar que houve poucas publicações especializadas. Mello e Novais (1998) apontam que desde o período pós-guerra ocorreu uma expansão da imprensa brasileira, e "empresas jornalísticas transformaram-se em umas poucas grandes organizações capitalistas, protegidas também por barreiras à entrada de novos competidores" (MELLO e NOVAIS, 1998, p. 639). Entretanto, tais barreiras não impediram a abundância de publicações e a ampliação do público leitor em todas as faixas etárias e classes sociais.

Surgida em um momento de turbulência econômica, política e cultural, SOMTRÊS viu o esgotamento do chamado "milagre brasileiro" e o início da "década perdida", apelido dado aos anos de 1980 devido às constantes crises econômicas que assolaram o Brasil. Sem embargo, era destinada à um público elitizado, que poderia comprar as últimas novidades em equipamentos de som de vídeo, podendo até mesmo empreender viagens internacionais. Isso não impedia, entretanto, que seus leitores não consumissem produtos piratas, uma preocupação constante de suas páginas.

Em matéria sobre a chegada da era do vídeo no Brasil, a publicação não consegue ter uma postura clara no que concerne às possibilidades de efetuar cópias caseiras com a novidade do aparelho de videocassete, ora incentivando, ora condenando tais ações, mas nunca deixando de informar seu público sobre as novidades do mundo da música e vídeo.

\section{Referências}

BAUMAN, Zygmunt. Vida para consumo: a transformação das pessoas em mercadoria. Rio de Janeiro: Zahar, 2008.

BENJAMIN, Walter. La obra de arte en la época de su reproductibilidad técnica.Editorial Itaca. México, D. F., 2003.

HEYLIN, Clinton. Bootleg: the secret history of the other recording industry. New York: St. Martin's Press, 1994. 
LADEIRA, Alexandre Gouvêa. O bom gosto pelas margens: motivações sociais no consumo de produtos piratas. Tese de Doutorado. Faculdade de Filosofia e Ciências Humanas da Universidade Federal de Minas Gerais: Belo Horizonte: 2013.

MELLO, João Manuel Cardoso de, e NOVAIS, Fernando A. Capitalismo Tardio e Sociabilidade Moderna. In: História da Vida Privada no Brasil (vol. 4): contrastes da intimidade contemporânea. SCHWARCZ, Lilia Moritz (Org.). São Paulo: Companhia das Letras, 1998.

NAPOLITANO, Marcos. 1964: História do Regime Militar Brasileiro. São Paulo: Contexto, 2014.

ORTIZ, Renato. A moderna tradição brasileira. São Paulo: Brasiliense, 2001.

ORTIZ, Renato. Mundialização e cultura. São Paulo: Brasiliense, 2003.

RIDENTI, Marcelo. Cultura e política:os anos 1960-1970 e sua herança. In: O Brasil Republicano, vol. 4. O tempo da ditadura: regime militar e movimentos sociais em fins do século $X X$. Jorge Ferreira e Lucilia de Almeida Neves (Orgs). Rio de Janeiro: Civilização Brasil, 2013.

SANTOS, Christiano Rangel dos. Pirataria musical: entre o ilícito e o alternativo. Dissertação de Mestrado. Universidade Federal de Uberlândia: Uberlândia , 2010.

SILVA, Francisco Carlos Teixeira da. Crise da ditadura militar e processo de abertura política no Brasil, 1974-1985. In: O Brasil Republicano, vol. 4. O tempo da ditadura: regime militar e movimentos sociais em fins do século XX. Jorge Ferreira e Lucilia de Almeida Neves (Orgs). Rio de Janeiro: Civilização Brasil, 2013.

\section{Fontes primárias}

Revista SOMTRÊS, São Paulo, no 01, jan. de 1979. Acervo da Sala Sérgio Milliet. Biblioteca Mário de Andrade, São Paulo, SP.

Revista SOMTRÊS, São Paulo, no 4, abr. 1979. Acervo da Sala Sérgio Milliet. Biblioteca Mário de Andrade, São Paulo, SP.

Revista SOMTRÊS, São Paulo, $n^{0}$ 8, ago. 1979. Acervo da Sala Sérgio Milliet. Biblioteca Mário de Andrade, São Paulo, SP.

Revista SOMTRÊS, São Paulo, ${ }^{0}$ 13, jan. de 1980. Acervo da Sala Sérgio Milliet. Biblioteca Mário de Andrade, São Paulo, SP.

Revista SOMTRÊS, São Paulo, no 28, abr. de 1981. Acervo da Sala Sérgio Milliet. Biblioteca Mário de Andrade, São Paulo, SP. 